\section{Postoperative complications in children undergoing video-assisted gastrostomy tube placement correlated to their age and diagnosis}

\author{
Helén Sjöwie, Malin Mellberg, \\ Einar Arnbjörnsson, \\ Department of Pediatric Surgery, Skåne \\ University Hospital, Lund and Lund \\ University, Sweden
}

\section{Abstract}

Gastrostomy tube placements in children are associated with frequent postoperative complications. Children with gastrostomy tubes are frequent visitors to the emergency department and outpatient clinic. The aim of this study was to determine the incidence of postoperative gastrostomy complications and disclose if these were correlated to the patients' age and diagnosis. This is a prospective study of children who had undergone laparoscopic gastrostomy tube placement from June 2006 through March 2011. Patient demographics, comorbidities, and complications were collected. Data were analyzed by Fisher's exact test. $\mathrm{P}<0.05$ is considered significant. One hundred and sixty-two children were evaluated, with the majority of patients $<2$ years of age (106/162). All the patients had undergone laparoscopic-assisted gastrostomy with double U-stitch technique. Granulation tissue, vomiting, infection, leakage were the most common postoperative complications. The majority of patients with these complications had full resolution by the sixth postoperative month. Tube dislodgement was a complication, occurring 16 times in 14 of the patients (10\%) and resulting in 16 emergency department (ED) visits. Diagnoses were predictive of complications, and age and gender were not. Granulation tissue, vomiting, infection, leakage and tube dislodgement are complications after gastrostomy placement in children. The age of the child, was not predictive of complications but children with congenital cardiac malformation and malignant diseases had more frequent postoperative complications.

\section{Introduction}

Gastrostomy tube placement is a common surgical procedure performed in children. This procedure can be associated with many early and late complications. Complications have been reported in up to $83 \%$ of children with gastrostomy tubes. ${ }^{1-3}$ Primary laparoscopic or video-assisted placement of gastrostomy buttons for feeding tubes is a safe and simple technique and the preferred method of gastrostomy in children. ${ }^{4-10}$

The surgeons performing this procedure claim that the operative intervention is easier in younger children because of the thinner abdominal wall of the small child. The question that arises is whether this is reflected in fewer postoperative complications in the infant group. Can findings of differences in the frequency of postoperative complications be used in preoperative counseling? Are there any age or diagnosis groups of children that should not be subjected to the operative intervention needed for creating a gastrostomy?

This subject has been retrospectively studied $^{11}$ in children using different techniques for the operation including the open procedure, laparoscopic assisted technique and laparoscopic technique and even including children undergoing coincidental procedures. The results showed that gender, age and even operative technique were not predictive of the frequency of complications. We are not aware of similar prospective reports in the literature, using the technique described here, comparing infants, younger than two years of age with older children, or studying complications in different groups with different diagnosis.

\section{Materials and Methods}

This is a prospective study of children who had undergone gastrostomy tube placement using the previously described U-stitch method. ${ }^{12,13}$ The method used here includes the use of a video-assisted technique. A 2-5 mm video optic is introduced into the abdominal cavity by a mini laparotomy through the umbilicus (Figure 1) and the stomach is visualized (Figure 2). At the place chosen for the gastrostomy a $5 \mathrm{~mm}$ laparoscopy trocar is introduced into the abdominal cavity under the direct vision through the video endoscope. Through the $5 \mathrm{~mm}$ port a grasper is introduced and used to grasp the anterior wall of the stomach (Figure 3). Withdrawing the $5 \mathrm{~mm}$ trocar and the grasper exteriorizes the stomach wall. The stomach is fixated to the abdominal wall by using a double U-stitch suture (Figure 4). The suture starts on the stomach wall, continues from inside out through the abdominal wall through one of the help incisions $1 / 2$ centimeter from the gastro stoma, turns back through the same help incision and runs again through the stomach wall. Then it makes another turn through the help incision on the other side finishing through the stomach wall at the same place as it started. The double
Correspondence: Einar Arnbjörnsson, Department of Pediatric Surgery, Skåne University Hospital in Lund, 22185 Lund, Sweden. Tel. +46.706496380 .

E-mail: einar.arnbjornsson@telia.com

Key words: gastrostomy, laparoscopy, children, gastrostomy button.

Acknowledgements: we are indebted to Gillian Sjödahl, Lexis English for Writers, Lund, Sweden, for linguistic revision of the manuscript and the Competence Centre for Clinical Research, University Hospital, in Lund, Sweden for statistical advice.

Received for publication: 28 September 2011. Revision received: 13 March 2012.

Accepted for publication: 20 March 2012.

This work is licensed under a Creative Commons Attribution NonCommercial 3.0 License (CC BYNC 3.0).

(C) Copyright H. Sjöwie et al., 2012

Licensee PAGEPress, Italy

Gastroenterology Insights 2012; 4:e5

doi:10.4081/gi.2012.e5

U-stitch is tightened after the stomach has been opened and the gastrostomy-button has been introduced and put in place (Figure 5). A gastroscopy shows the gastrostomy button in place in the stomach (Figure 6), without interfering with the flow of the stomach content out through the pylorus.

The study period was from June 2006 through March 2011 at a tertiary clinic for Pediatric Surgery. Patient demographics, comorbidities, and complications were collected. All the children were followed-up prospectively during the first postoperative days in the hospital and at one and six months after the operation. The endpoint of the study was six months after the surgery. Additional follow-ups were performed any time at the request of the child's guardians. All complications were documented according to a standardized protocol by a specially trained nurse. The postoperative complications requiring treatment that we registered included:

granuloma resulting in intervention, such as cauterizations;

infection requiring antibiotics;

a leakage that required further management, including a change to a new button with a different length or size, or a change of volume in the balloon of the button, or frequent, greater than two times a day, change of dressings.

\section{Ethical considerations}

Intention to treat was the main analysis strategy and encompassed all the patients. 
This study included follow-up of only the patients operated on routinely. The protocol was designed to meet the legislative documentation required in the country of origin. The regional research ethics committee approved the study (registration number 2010/49). The data are presented in such a way that it is impossible to identify any single patient and therefore it was not necessary to obtain approval from the individual patients.

\section{Statistical considerations}

Based on our previously published data using the frequency of postoperative complications as the primary endpoint, a sample size of 75 patients and 75 controls was calculated as sufficient to perform a $t$-test, obtaining a significant difference when the mean difference is 0.3 . The alpha level for rejecting the null hypothesis of mean difference equal to zero is $5 \%$ and the power is above $80 \%$. Fisher's exact test and Exact Contingency Table two-tailed were used. All statistical computations were made using SPSS version 15 (SPSS, Inc., Chicago, IL, USA). A value of $\mathrm{P}<0.05$ was considered significant.

\section{Results}

The results are summarized in Table 1, showing the demographic data on all the included children. A summary of the frequency of minor complications after a video-assisted gastrostomy operation from the perspective of their fate over time is shown in Table 2. A minor complication was not always directly present postoperatively. It could occur later during the progression of the patient. This suggests that the minor complications were not only due to the insertion of the gastrostomy button, but were partly due to the child's clinical situation during the course of their underlying disease. Vomiting was an exception to the rule that the minor complications reduced in frequency with time. The gastrostomy operation does not significantly influence the vomiting which probably depends on the underlying disease and its progress as well as the child's clinical situation.

The described method used for the operation is considered easier the smaller the child and the thinner the abdominal wall. Therefore it was of interest to compare the infants, less than two years of age, with those who were older, with respect to postoperative complications. This comparison is summarized in Table 3 disclosing no practical differences and not suggesting that infants are less prone to postoperative complications, despite the surgeons' impression that the operative intervention is easier with these small patients. This remains true even after calculation using the Spearman rank correlation test. Table 4 summarizes the frequency of minor complications in different groups of diagnoses. The postoperative complications of infection and leakage were most common in the children with malignancy, congenital cardiac malformations and respiratory insufficiency while the problems with granuloma and vomiting were found to be equal in all groups of diagnosis.

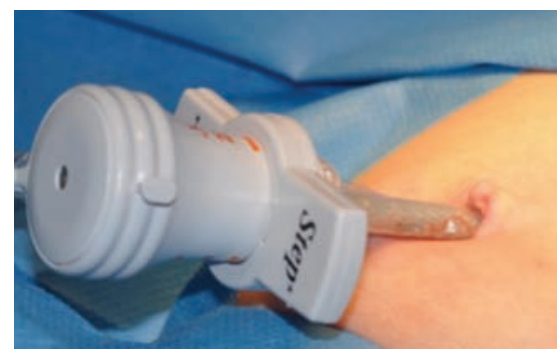

Figure 1. Two, three or five millimeters trocar is introduced by a mini laparotomy through the umbilicus.

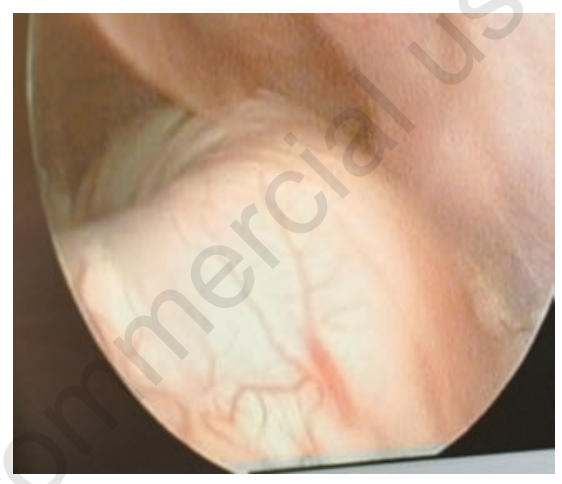

Figure 2. The stomach is visualized when the liver is lifted up.

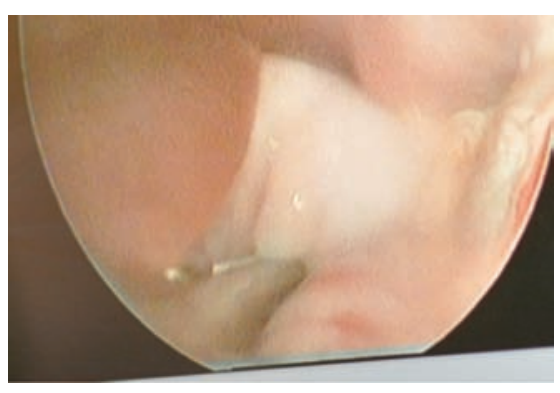

Figure 3. Where the operating surgeon decides to place the gastrostomy on the abdominal wall a trocar is placed and through the latter a two, three or five millimeter grasper is introduced. Using the latter the stomach wall is grasped, where the surgeons decide to place the gastrostomy on the stomach, and pulled out through the hole in the abdominal wall left when the trocar is withdrawn.

\section{Discussion}

The results show that age does not influence the frequency of postoperative complications after a laparoscopic gastrostomy operation in children. The findings are of importance in preoperative counseling and may theoretically have an influence on the selection of

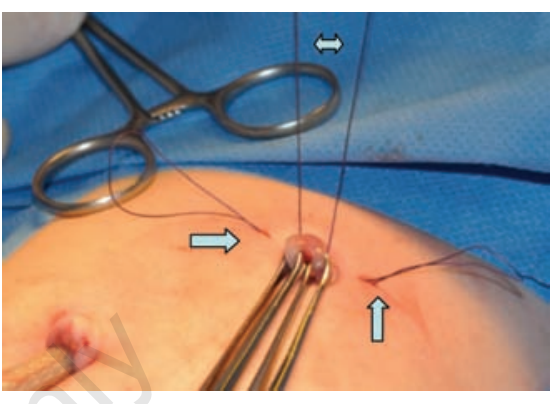

Figure 4. The photo is showing the exteriorized stomach held by graspers. The right and left arrows are pointing to the small help incisions used for placing the U-stitch suture, the ends of which are indicated by the double arrow. The double U-stitch suture forms a purse-string suture around the gastro stoma on the stomach.

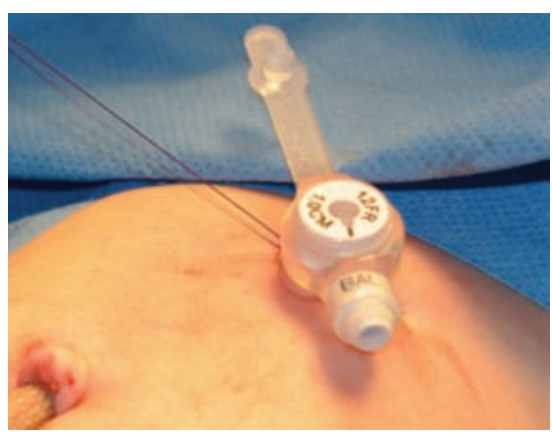

Figure 5. The gastrostomy button in place on the abdominal wall.

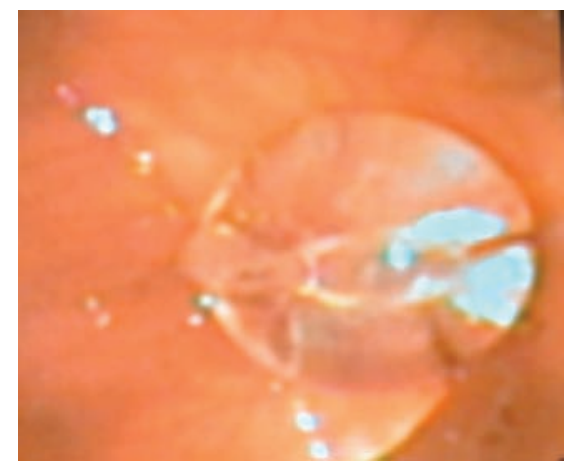

Figure 6. A view from the gastroscopy showing the balloon on the tip of the gastrostomy button. 
which patients can be subjected to operative intervention by a video-assisted gastrostomy. The findings support the results of previous publications. ${ }^{12,13-16}$ The fact that the gastrostomy in children is hampered by frequent minor complications is well known, and these complications are seen after all techniques used for the construction of a gastrostomy. This suggests that the method used for the operation has less importance for the appearance of minor complications than the common factor for the gastrostomies, i.e. the placement of a corpus alien, the gastrostomy button, through the abdominal and the stomach wall. The results demonstrate that minor postoperative complications are most frequent in the group of children with congenital cardiac anomaly and in those with malignancy. These findings are supported by previous reports on gastrostomies in children with malignancies ${ }^{17}$ and congenital cardiac malformations. ${ }^{18}$

The results do not account for the different type of congenital cardiac anomalies, nor where the children were in the treatment, preoperatively before any corrective operative cardiac intervention, after a first operation, waiting for the next and/or the final/definitive operative intervention or if the cardiac surgery was already done and considered finalized, leaving the child with only medical treatment for the time to come. The importance of the child's state of the cardiac operative treatment for the postoperative gastrostomy complication remains to be studied.

The results do not correlate the children's type of malignancy nor the state of their malignancy treatment. This leaves another unanswered question. Whether the type of malignancy, for example solid tumor or hematologic malignancy, influences the frequency of postoperative complications after a video-assisted gastrostomy operation, cannot be answered by the data presented here. The children with cerebral pares and metabolic diseases are a widely heterogeneous group. In these different diagnoses and situations there may be many confounding factors that may or may not influence the type and frequency of postoperative

Table 1. The demography of the 162 children included in the study. All figures are given in median and (range).

\begin{tabular}{|c|c|}
\hline Age in years & $\begin{array}{c}1 \text { year } \\
\text { (1 month-14 years) }\end{array}$ \\
\hline Weight in $\mathrm{kg}$ & $9(3-41)$ \\
\hline SD* & $-2(-7-2)$ \\
\hline Length in $\mathrm{cm}$ & $75(36-162)$ \\
\hline SD* & $-2(-7-2)$ \\
\hline Body mass index $\left(\mathrm{kg} / \mathrm{m}^{2}\right)$ & $15(11-22)$ \\
\hline \multicolumn{2}{|c|}{$\begin{array}{l}\text { The individual weight was assessed by using charts for gender- and } \\
\text { age-matched growth standard deviation (SD) scores for Swedish } \\
\text { children. Age was approximated to age in months, and weight scores } \\
\text { were approximated to the closest whole number in standard devia- } \\
\text { tion. These figures are expressed as weight-for-age Z-scores calcu- } \\
\text { lated as: (actual weight-mean weight)/standard deviation (12), } \\
\text { according to the nationally standardized weight curves (13). }\end{array}$} \\
\hline
\end{tabular}

Table 2. A summary of the minor complications found at prospective follow-up in $\mathbf{1 6 2}$ children included.

\begin{tabular}{lccr} 
Minor complications & \multicolumn{2}{c}{ After } & P** \\
In $\mathbf{1 6 2}$ children & $\mathbf{1}$ month & $\mathbf{6}$ months & \\
Granuloma & $42(26 \%)$ & $24(15 \%)$ & 0.0186 \\
Vomiting & $38(23 \%)$ & $24(15 \%)$ & 0.0658 \\
\hline Infection & $36(22 \%)$ & $5(3 \%)$ & $<0.0001$ \\
$\quad$ treated with antibiotics & $24(15 \%)$ & $2(1 \%)$ & $<0.0001$ \\
Leakage & $26(16 \%)$ & $6(4 \%)$ & 0.0002 \\
\hline Tube dislodgement & $8(5 \%)$ & $10(6 \%)$ & 0.8092 \\
\hline *Satistical method: Fisher's exact test. & & &
\end{tabular}

Table 3. Comparison of the number of minor postoperative complications between infants, < 2 years, and older children.

\begin{tabular}{|c|c|c|c|c|c|}
\hline \multirow{3}{*}{$\begin{array}{l}\text { Minor complications } \\
n=162 \\
\text { Age in years, median (range) } \\
\text { Weight in } \mathrm{kg} \text {, median (range) }\end{array}$} & \multicolumn{3}{|c|}{ Children's age groups } & & *P after \\
\hline & \multicolumn{2}{|c|}{$1(0-2)$} & \multicolumn{2}{|c|}{$5(2-14)$} & \\
\hline & \multicolumn{2}{|c|}{$8(2-14)$} & \multicolumn{2}{|c|}{$16(9-42)$} & \\
\hline \multirow[t]{2}{*}{ Number of } & \multicolumn{2}{|c|}{ After } & \multicolumn{2}{|c|}{ After } & \\
\hline & 1 month & 6 months & 1 month & 6 months & 1 month/6 months \\
\hline Granuloma & 29 & 15 & 13 & 9 & $0.5801 / 0.8172$ \\
\hline Vomiting & 28 & 17 & 10 & 7 & $0.2477 / 0.7083$ \\
\hline Infection & 20 & 4 & 16 & 1 & $0.1691 / 0.6599$ \\
\hline Leakage & 15 & 2 & 11 & 4 & $0.3760 / 0.1832$ \\
\hline
\end{tabular}

* Satistical method: Fisher's exact test.

Table 4. The complications found in the included group of 162 children, correlated to the diagnosis groups. The children had comorbidity in the form of epilepsy which was found in $27(17 \%)$, ventricular - peritoneal shunt in $9(5 \%)$ and a mitochondrial disease in 6 (4\%) children.

\begin{tabular}{|c|c|c|c|c|c|c|c|}
\hline $\begin{array}{l}\text { Diagnosis in } \\
162 \text { children }\end{array}$ & $\begin{array}{l}\text { Cerebral } \\
\text { pares }\end{array}$ & $\begin{array}{l}\text { Cardiac } \\
\text { malformation }\end{array}$ & $\begin{array}{l}\text { Metabolic disease } \\
\text { and syndrome }\end{array}$ & $\begin{array}{l}\text { Malformation of } \\
\text { the gastro-intestinal tract }\end{array}$ & Malignancy & $\begin{array}{l}\text { Respiratory } \\
\text { insufficiency }\end{array}$ & $\mathbf{P}^{*}$ \\
\hline Number (\%) & $68(42 \%)$ & $29(18 \%)$ & 39 (24\%) & $11(7 \%)$ & $8(5 \%)$ & $7(4 \%)$ & \\
\hline Granuloma & $15(22 \%)$ & $9(31 \%)$ & $7(18 \%)$ & $3(27 \%)$ & $5(63 \%)$ & $3(43 \%)$ & 0.1130 \\
\hline Vomiting & $13(19 \%)$ & $8(28 \%)$ & $5(13 \%)$ & $1(9 \%)$ & $2(25 \%)$ & $1(14 \%)$ & 0.6542 \\
\hline Infection & $7(10 \%)$ & $6(21 \%)$ & $4(10 \%)$ & $1(9 \%)$ & $5(63 \%)$ & $2(29 \%)$ & 0.0090 \\
\hline Leakage & $4(6 \%)$ & $5(17 \%)$ & $4(10 \%)$ & $1(9 \%)$ & $2(25 \%)$ & $3(43 \%)$ & 0.0411 \\
\hline
\end{tabular}

*Statistical method: Exact Contingency table. 
complications after gastrostomy operations. The existence of ventricular-peritoneal shunts ${ }^{19}$ has been studied and not found to cause an increase in the frequency of postoperative complications after video-assisted gastrostomy.

The children with gastrointestinal malformations are hit by fewer infections and leakage as well as vomiting compared to the other children. However, they do not differ from the other groups of children regarding the formation of granuloma. This may partly be explained by the fact that these children often do not have concomitant diseases making them more vulnerable to infection or leakage, while the formation of granuloma is merely caused by the existence of the gastrostomy button in the stoma. The children with respiratory insufficiency and those with tracheostomies are well known to have postoperative problems as demonstrated by the finding in this study. These children have considerable problems with their gastrostomies owing to increased abdominal pressure because of labored breathing leading to increased leakage around the gastrostomy. These findings are supported by previous findings. ${ }^{2}$ The problem with leakage may be influenced by using smaller gastrostomy buttons. ${ }^{20}$ The way of performing a gastrostomy in children described here is certainly not the only one. Nor is it the definite final solution to the problem of performing a gastrostomy operation in children causing as few postoperative problems as possible. In a retrospective study on the postoperative complications after a gastrostomy operation on children the authors found that the operative technique did not have any effect on the postoperative complication rates among children. ${ }^{11}$ This may be true regarding minor postoperative problems such as granuloma, infection, leakage and dislodgement of the gastrostomy button. On the other hand, there are significant differences between the major complication rates between the percutaneous endoscopic gastrostomy (PEG) and the video-assisted gastrostomy related to the blind puncture through the abdominal cavity included in the PEG technique. ${ }^{3}$

\section{Conclusions}

As shown here, the minor complications are frequent during the first postoperative month. These do not disappear completely after six months and in our experience they can be a problem even after the first six postoperative months. This is important information to bear in mind at pre-operative counseling before a gastrostomy operation. Furthermore, the children with congenital cardiac malformation, respiratory insufficiency and those with malignancy are most frequently hit by minor postoperative complications after a video-assisted gastrostomy in children.

\section{References}

1. Arnbjörnsson E, Larsson LT, Lindhagen T. Complications of laparoscopy-aided gastrostomies in pediatric practice. J Pediatr Surg 1999;34:1843-6.

2. Backman T, Sjövie H, Kullendorff CM, et al. Correlation between the preoperative state of nutrition and the frequency of postoperative problems after video-assisted gastrostomy in children. Gastroenterol Insights 2009;1:e2.

3. Lantz M, Hultin Larsson H, Arnbjörnsson E. Literature review comparing laparoscopic and percutaneous endoscopic gastrostomies in a pediatric population. Int $\mathrm{J}$ Pediatr. 2010;2010:507616.

4. Aprahamian CJ, Morgan TL, Harmon CM, et al. U-stitch laparoscopic gastrostomy technique has a low rate of complications and allows primary button placement: experience with 461 pediatric procedures. J Laparoendosc Adv Surg Tech A 2006;16: 643-9.

5. Fanelli RD, Ponsky JL. A simplified technique for percutaneous endoscopic gastrostomy. Surg Endosc 1992;6:261-2.

6. Jones VS, La Hei ER, Shun A. Laparoscopic gastrostomy: the preferred method of gastrostomy in children. Pediatr Surg Int 2007;23:1085-9.

7. Kellnar ST, Till H, Bohn R. Laparoscopically assisted performance of gastrostomy-a simple, safe and minimal invasive technique. Eur J Pediatr Surg 1999;9:297-8.

8. Rothenberg SS, Bealer JF, Chang JH. Primary laparoscopic placement of gastrostomy buttons for feeding tubes. A safer and simpler technique. Surg Endosc 1999;13:995-7.

9. Tomicic JT, Luks FI, Shalon L, Tracy TF. Laparoscopic gastrostomy in infants and children. Eur J Pediatr Surg 2002;12:107-10.

10. Zamakhshary M, Jamal M, Blair GK, et al. Laparoscopic vs percutaneous endoscopic gastrostomy tube insertion: a new pediatric gold standard? J Pediatr Surg 2005; 40:859-62.

11. Naiditch JA, Lautz T, Barsness KA. Postoperative complications in children undergoing gastrostomy tube placement. J Laparoendosc Adv Surg Tech A 2010; 20:781-5.

12. Backman T, Sjövie H, Kullendorff CM, Arnbjornsson E. Continuous double Ustitch gastrostomy in children. Eur $\mathrm{J}$ Pediatr Surg 2010;20:14-7.

13. Backman T, Mellberg M, Sjöwie $\mathrm{H}$, Anderberg M and Arnbjörnsson E. VideoAssisted Gastrostomy in Children, Gastrostomy, Pavel Kohout (Ed.) 2011. Available from: http://www.intechopen. com/articles/show/title/video-assisted-gastrostomy-in-children

14. Liou TG, Adler FR, Fitzsimmons SC, et al. Predictive 5-year survivorship model of cystic fibrosis. Am J Epidemiol 2001;153: 345-52.

15. Albertsson-Wikland K, Karlberg J. Natural growth in children born small for gestational age with and without catch-up growth. Acta Paediatr Suppl 1994;399:6471.

16. Backman T, Arnbjörnsson E, Berglund Y, Larsson LT. Video-assisted gastrostomy in infants less than 1 year. Pediatr Surg Int 2006;22:243-6.

17. Arnbjörnsson E, Backman T, Mörse H, et al. Complications of video-assisted gastrostomy in children with malignancies or neurological diseases. Acta Paediatr 2006;95: 467-70.

18. Norén E, Gunnarsdóttir A, Hanséus K, Arnbjörnsson E. Laparoscopic gastrostomy in children with congenital heart disease. J Laparoendosc Adv Surg Tech A 2007;17: 483-9.

19. Backman T, Berglund Y, Sjövie H, Arnbjörnsson E. Complications of videoassisted gastrostomy in children with or without a ventriculoperitoneal shunt. Pediatr Surg Int 2007;23:665-8.

20. Sjövie H, Larsson LT, Arnbjörnsson E. Postoperative gastrostomy site leakage correlated to the dimension of the gastrostomy button in children. Gastroenterol Insights 2010;2:e9. 